University of Nebraska - Lincoln

DigitalCommons@University of Nebraska - Lincoln

PreColumbian Textile Conference VIII /

Jornadas de Textiles PreColombinos VIII (2019)

Centre for Textile Research

$6-2020$

Recontextualizando el patrimonio arqueológico: los textiles

paracas descubiertos por Engel en Cabezas Largas

Jessica Lévy Contreras

Follow this and additional works at: https://digitalcommons.unl.edu/pctviii

Part of the Art and Materials Conservation Commons, Fiber, Textile, and Weaving Arts Commons, Indigenous Studies Commons, Latin American Languages and Societies Commons, Museum Studies Commons, and the Other History of Art, Architecture, and Archaeology Commons

This Article is brought to you for free and open access by the Centre for Textile Research at DigitalCommons@University of Nebraska - Lincoln. It has been accepted for inclusion in PreColumbian Textile Conference VIII / Jornadas de Textiles PreColombinos VIII (2019) by an authorized administrator of DigitalCommons@University of Nebraska - Lincoln. 


\title{
Recontextualizando el patrimonio arqueológico: los textiles paracas descubiertos por Engel en Cabezas Largas
}

\author{
Jessica Lévy Contreras
}

Investigadora independiente

jessica.levy@pucp.pe

\section{Resumen}

El archivo de Frédéric Engel, arqueólogo suizo quien trabajó en la costa sur del Perú entre los años 1950 y 1960, representa un patrimonio documental importante conservado en el Museo Nacional de Antropología, Biodiversidad, Agricultura y Alimentación (MUNABA) de la Universidad Nacional Agraria La Molina en Lima. Gracias a la revisión de los registros gráficos y fotográficos de las excavaciones realizadas en Cabezas Largas, sitio ubicado en la Península de Paracas, y particularmente de los materiales hallados en la tumba T.27, este artículo presenta los principales textiles asociados a la parafernalia ritual de siete fardos funerarios para tratar de entender mejor las técnicas de manufactura y las prácticas mortuorias del final del Horizonte Temprano en la región (fases Ocucaje 8, 9 y 10). Esta investigación pretende demostrar la relevancia de los datos recopilados en vista de la recontextualización y del análisis de los textiles de la tumba T.27.

Palabras claves: Textiles paracas, Frédéric Engel, tumba T.27, Cabezas Largas, recontextualización del patrimonio arqueológico, análisis de contexto mortuorio.

\begin{abstract}
The archive of Frédéric Engel, Swiss archaeologist who worked in the South coast of Peru between the years 1950 and 196o, represents an important documentary heritage conserved in the Museo Nacional de Antropología, Biodiversidad, Agricultura y Alimentación (MUNABA) of the Universidad Nacional Agraria La Molina in Lima. Based on the review of the graphic and photographic records of the excavations conducted in Cabezas Largas, site located in the Paracas Peninsula, and particularly the materials found in the tomb T.27, this paper presents the principal textiles associated with the ritual paraphernalia of seven funerary bundles to try to better understand manufacturing techniques and mortuary practices from the end of the Early Horizon in the region (phases Ocucaje 8, 9 and 10). This research intends to demonstrate the relevance of the data reassembled for the recontextualization and analysis of the textiles of tomb T.27.
\end{abstract}

Keywords: Paracas textiles, Frédéric Engel, tomb T.27, Cabezas Largas, recontextualization of archaeological heritage, mortuary analysis.

\section{Résumé}

Les documents d'archives de Frédéric Engel, archéologue suisse qui a travaillé sur la côte sud du Pérou entre les années 1950 et 196o, représentent un patrimoine documentaire important conservé au Museo Nacional de Antropología, Biodiversidad, Agricultura y Alimentación (MUNABA) de l'Universidad Nacional Agraria La Molina à Lima. Grâce à la révision des registres graphiques et photographiques des fouilles réalisées à Cabezas Largas, site localisé dans la Péninsule de Paracas, et particulièrement des objets découverts dans la tombe T.27, cet article présente les principaux tissus associés à l'attirail rituel de sept fardos funéraires pour essayer de mieux comprendre les techniques de manufacture et les pratiques mortuaires de la fin de l'Horizon Ancien dans la région (phases Ocucaje 8, 9 et 10). Cette étude prétend démontrer la pertinence des données recueillies pour recontextualiser et analyser les textiles de la tombe T.27.

Mots clés: Textiles paracas, Frédéric Engel, tombe T.27, Cabezas Largas, recontextualisation du patrimoine archéologique, analyse de contexte mortuaire.

DOI: 10.32873/unl.dc.zea.1202

Published in PreColumbian Textile Conference VIII / Jornadas de Textiles PreColombinos VIII, ed. Lena Bjerregaard and Ann Peters

(Lincoln, NE: Zea Books, 2020). https://digitalcommons.unl.edu/zeabook/ 


\section{Introducción}

Esta investigación empezó de manera indirecta entre febrero y mayo de 2016, cuando se realizó la conservación y el montaje de un conjunto de materiales paracas para el nuevo $\mathrm{Mu}-$ seo de Sitio "Julio C. Tello" de Paracas (en adelante, MSP) inaugurado en julio del mismo año. Los materiales intervenidos con Luis Alberto Peña Callirgos, en particular los textiles, despertaron nuestro interés por sus características técnicas y tratamiento decorativo y curiosidad por su contexto arqueológico. Hallados en diferentes sitios de la Península de Paracas por el arqueólogo suizo Frédéric Engel, quien trabajó en la costa sur del Perú entre los años 1950 y 196o, estos artefactos ofrecen datos inéditos para estudiar la cultura Paracas, del cual sabemos que existen registros gráficos y fotográficos conservados en el Museo Nacional de Antropología, Biodiversidad, Agricultura y Alimentación (en adelante, MUNABA) de la Universidad Agraria La Molina en Lima, institución que apoyó los trabajos de Engel en todo el Perú y su difusión a través del Centro de Investigaciones de Zonas Áridas (CIZA).

En el marco del I Coloquio de Arqueología del Museo "Julio C. Tello" de Paracas, organizado en abril de 2018, se presentó en colaboración con Katherine Román Aquino la recontextualización y el análisis de una de las piezas más emblemáticas de esta colección, el manto pintado MSP0043-02. Se descubrió que el material formaba parte del ajuar funerario asociado al Fardo VII de la tumba T.27 de Cabezas Largas, contexto excavado por Engel y su equipo entre julio y agosto de 1959 (Lévy Contreras y Román Aquino 2018). Los resultados obtenidos a partir de la recopilación de los datos arqueológicos procedentes del archivo de Engel en el MUNABA abrieron paso para desarrollar la presente investigación, la misma que tiene como la finalidad de recontextualizar y analizar todos los materiales encontrados en la tumba.

En efecto, la mayoría de los artefactos hallados en la tumba T.27 no fueron publicados ni analizados desde una perspectiva formal, decorativa o comparativa, salvo algunos ejemplares, probablemente elegidos por su carácter excepcional, mostrando el detalle de una pieza sin su rótulo y/o datos de contexto completos (Engel 1966: 177 Fig. 49 A, 180 Figs. 49 C y D, 182 Fig. 49 H, 183 Figs. 49 I y J, 216 Fig. 61; 1991: 97 Figs. 6o, 61 y 62, 98 Fig. 64, 102 Figs. 70 y 71, 113 Figs. 84 y 87, 114 Fig. 89). Dato aún más curioso cuando el dibujo de perfil de la tumba T.27 fue publicado y descrito por Engel (1966: 189 Fig. 53, 203-204). Estos materiales, que son familiares para los investigadores que traten de la cultura Paracas, siguen generando preguntas acerca de su descubrimiento puesto que se encuentran hoy descontextualizados y dispersos en diferentes museos del Perú.
Desde setiembre de 2018 se viene realizando un estudio pluridisciplinar exhaustivo sobre la tumba T.27 de Cabezas Largas a partir del análisis del archivo de Engel y de los materiales asociados al contexto en el MUNABA. Si bien faltan examinar algunas piezas en exposición en el MSP y otras en custodia en el Museo Regional de Ica "Adolfo Bermúdez Jenkins” (en adelante, MRI), esta investigación pretende demostrar la relevancia de los datos recuperados para estudiar el ajuar de cada fardo funerario y de la tumba en su conjunto y tratar de entender mejor las tradiciones estilísticas, las prácticas de producción y las costumbres funerarias de las últimas fases del Horizonte Temprano (fases Ocucaje 8, 9 y 10, aproximadamente entre 400 y 100 a.C.) en la región. Este artículo muestra por primera vez los resultados preliminares obtenidos sobre los textiles del contexto. Se eligió una selección de los artefactos más importantes que combinan diferentes elementos en formas y técnicas antes desconocidas para esta época y cultura. Tras haber explicado nuestra metodología para realizar los trabajos archivísticos en el MUNABA, se presenta la recontextualización y el análisis de los principales textiles de la tumba T.27 para abrir una discusión sobre los rituales mortuorios paracas comparando los datos de Engel a los obtenidos por otros estudiosos en la región.

\section{El análisis del archivo de Engel en el MUNABA}

El archivo de Engel se compone de varios documentos gráficos y fotográficos escritos en castellano, francés y/o inglés sobre la tumba T.27 de Cabezas Largas en el MUNABA. Se conservaron notas de campo manuscritas o escritas a máquina, varios catálogos de materiales, un registro de las fotografías realizadas con su número de negativo y descripción de los sitios o artefactos reproducidos, fotografías en blanco y negro de diversos tamaños, negativos, diapositivas en blanco y negro o en color, dibujos, mapas, informes, así como textos cortos, a veces corregidos e ilustrados, a manera de pruebas para futuras publicaciones. La riqueza de esta documentación se centra en las notas de campo y los inventarios de los materiales redactados por Engel, quien dirigió las investigaciones en Cabezas Largas y designó a Henning Bischof para supervisar la excavación de la tumba. Las notas de campo de Bischof, en particular sus descripciones, dibujos y análisis bioantropológico, realizados cuando asistió al desenfardelamiento de los individuos de la tumba T.27, resaltan por sus detalles puntuales y calidad científica dentro de los datos mencionados (Figura 1). La pluralidad de la información conservada se convierte en una fuente de información primordial para esta investigación.

Tras haber leído y traducido al castellano los registros gráficos de Engel y Bishof para gestionar la información con 


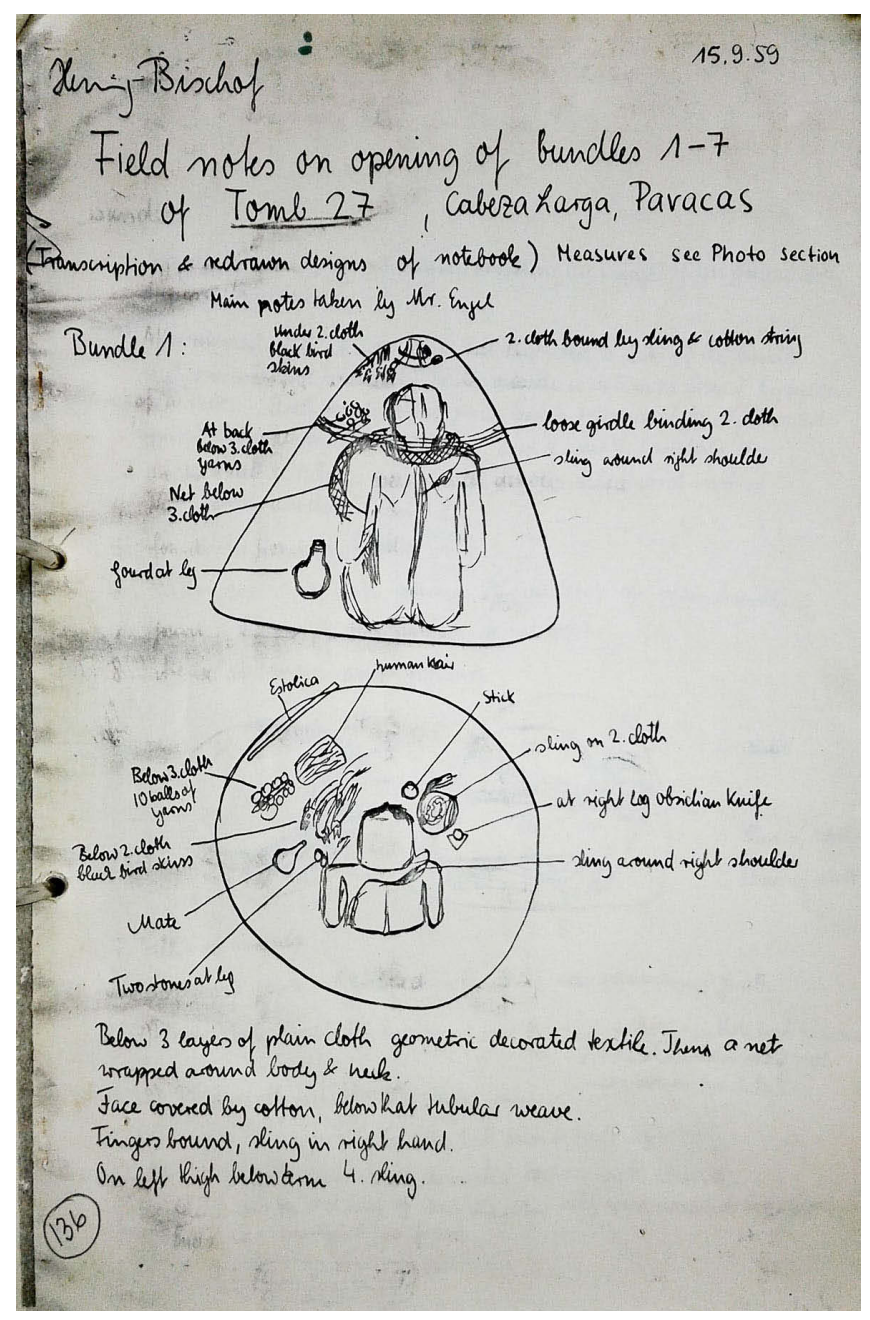

Figura 1: Primera página de las notas de campo tomadas por Bischof el 15 de setiembre de 1959 (Archivo de Engel, Lima [MUNABA] 14a-VI-3 Tumbas (B) f. 91: 136).

mayor facilidad, se cotejaron los datos obtenidos con los inventarios de los materiales de la tumba para identificar todos los objetos asociados al contexto y buscar las fotografías y los negativos originales de cada pieza. Aunque existen contradicciones entre ambos autores (Archivo de Engel, Lima [MUNABA] 14a-VI-3 Tumbas (B) f. 91: 111-161), esta etapa fue determinante para nuestro estudio porque permitió al mismo tiempo identificar y comprobar la validez de los rótulos de cada artefacto ${ }^{1}$. Por otra parte, gracias a la revisión de los catálogos elaborados para cada tipo de material descubierto en excavación, divididos según la tipología de Engel en Textiles (incluyendo fibra vegetal), Óseo (animal), Cerámica, Piedra [Lítico], Concha [Malacológico], Varios (entre otros hallazgos, óseo humano, metales y restos botánicos) y Madera, se buscaron las fichas de inventario de cada pieza procedente de la tumba. En esta labor aparecieron más documentos fotográficos y dibujos de los materiales. Se registraron en total más de 1200 documentos relacionados con el descubrimiento de la tumba T.27 de Cabezas Largas. Estos últimos fueron digitalizados e inventariados para acceder más fácilmente a su contenido y determinar su ubicación exacta en el archivo. Luego se comparó dichos resultados con las publicaciones de Engel $(1966,1991)$ para verificar la presencia de datos e ilustraciones sobre el contexto y el ajuar de la tumba.

Finalmente, se procedió al nuevo registro fotográfico y al análisis de los materiales de la tumba conservados en el MUNABA. La mayoría de las piezas se encuentran hoy en los depósitos del museo salvo unas excepciones que pertenecen a la muestra de la exposición permanente. La otra parte de la colección fue trasladada al antiguo Museo de Paracas para su inauguración en 1964 (Archivo de Engel, Lima [MUNABA] Catálogo Paracas). Si bien algunos de estos materiales siguen siendo parte de la exposición permanente del MSP, los otros fueron dados en custodia al MRI para ser almacenados. Cuando el estado de conservación de las piezas lo permitía, se efectuó la limpieza mecánica y el cambio de embalaje de los materiales del MUNABA. Lamentablemente, la mayoría de los textiles presentan daños irreparables, principalmente por su carbonización avanzada, su consolidación con pegamento y/o hilos en soportes de papel acartonado y su apolillamiento. Es posible que los artefactos no recibieron tratamientos de conservación preventiva después de su hallazgo, incluso si estos fueron fijados en bastidores para su exposición. Algunos montajes, que permanecen hasta la fecha, fueron registrados en las fotografías y las diapositivas de Engel y su equipo.

Resumiendo la información obtenida del archivo de Engel, se estima que cerca de 215 piezas conformaban la parafernalia ritual de la tumba T.27 de Cabezas Largas. Este número toma en cuenta los materiales recontextualizados tanto como los materiales indeterminados, es decir, las piezas cuyos números de inventario y/o datos de contexto no permiten saber con certeza a qué fardo funerario pertenece (Tabla 1). Los textiles representan $45 \%$ de la muestra total (Figura 2). Sin embargo, por problemas inherentes a la práctica arqueológica de la época y a la falta de sistematización de los datos recuperados, es muy probable que el número total de materiales hallados en la tumba sea más significativo. De facto, algunas piezas descritas en las notas de campo no aparecen en los inventarios generales y tampoco fueron dibujadas o fotografiadas. Además, las fotografías tomadas durante el desenfardelamiento de los individuos muestran a veces artefactos que no aparecen en otros registros gráficos o fotográficos asociados a la tumba.

1. Salvo algunas excepciones, se pudo corregir los rótulos de los materiales comparando sus números de inventario, sus descripciones y/o su imagen en cada documentación. 


\begin{tabular}{|c|c|c|c|c|c|c|c|c|c|c|}
\hline & \multicolumn{9}{|c|}{ Recontextualizados } & \multirow{2}{*}{ Indeterminados } \\
\hline Materiales & "Casa" & Tumba & Fardo I & Fardo II & Fardo III & Fardo IV & Fardo V & Fardo VI & Fardo VII & \\
\hline Textiles & 2 & 8 & 3 & 9 & 8 & 15 & 9 & 6 & 29 & 7 \\
\hline Óseo & - & 6 & - & 1 & 5 & 3 & - & 5 & 3 & - \\
\hline Cerámica & 3 & 2 & - & - & - & - & - & 1 & - & 1 \\
\hline Piedra [Lítico] & - & - & 4 & 1 & - & - & - & - & 1 & - \\
\hline Concha [Malacológico] & - & - & - & 4 & 3 & - & - & - & - & - \\
\hline Varios & - & 5 & 6 & 4 & 3 & 5 & 2 & 2 & 6 & 8 \\
\hline Madera & - & 16 & 6 & 2 & 1 & - & - & 2 & 3 & 5 \\
\hline
\end{tabular}

Tabla 1: Cuadro-resumen presentando los materiales recontextualizados e indeterminados de la tumba T.27 de Cabezas Largas (Jessica Lévy Contreras, elaborado a partir del Archivo de Engel, Lima [MUNABA]).

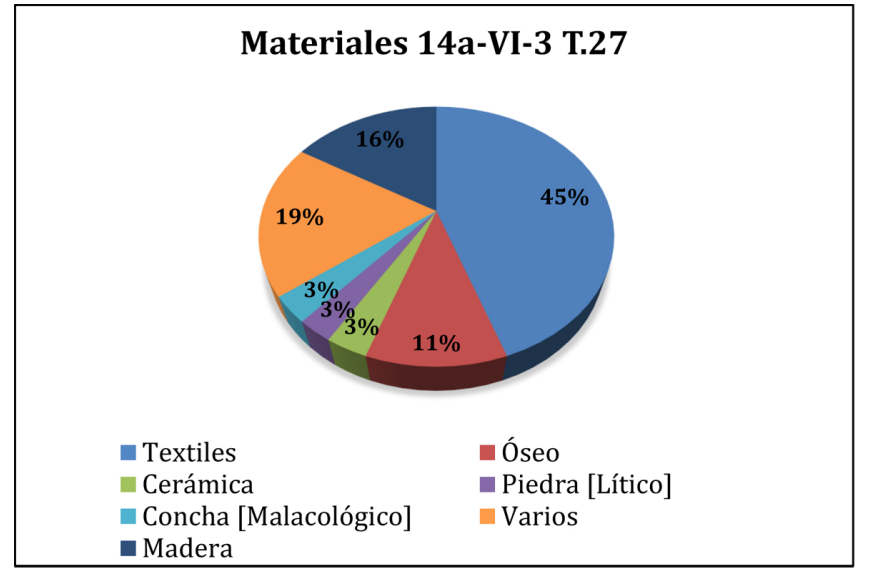

Figura 2: Proporción de materiales hallados en el contexto estudiado (Jessica Lévy Contreras, elaborado a partir del Archivo de Engel, Lima [MUNABA]).

\section{Hacia la recontextualización de la Tumba T.27 de Cabezas Largas}

La tumba T.27, con código de sitio 104 AG o 14a-VI-32 , se localiza en el sitio de Cabezas Largas - denominado también Arena Blanca - a unos metros de la Bahía de Paracas, entre los valles de Pisco e Ica en la costa sur del Perú. Ubicada en una de las terrazas de la Unidad III Corte Estratigráfico $\mathrm{V}$ del sitio ${ }^{3}$, la tumba fue descubierta de manera fortuita debido a que el relleno de esta cedió por el peso de un camión que pasó encima del sitio (Archivo de Engel, Lima [MUNABA], 14a-VI-3 (2) f. 89: 25). Al remover el relleno se encontró una capa de caliche y debajo de ella diversos materiales asociados a la tumba. Comparando el registro gráfico con los dibujos de campo de Engel y Bischof (Archivo de Engel, Lima [MUNABA], 14a-VI-3 (2) f. 89: 26-28; 14aVI-3 Tumbas (B) f. 91: 116-118 y 120), la estratigrafía de la tumba es discutible y parece aludir a la ampliación al oeste de las excavaciones. Engel comenta incluso en una de sus notas que se mantienen "incertidumbres" en los datos recolectados (Archivo de Engel, Lima [MUNABA], 14a-VI-3 Tumbas (B) f. 91: 147), posiblemente debido a la metodología empleada.

De forma rectangular, la tumba T.27 medía $3.15 \mathrm{~m}$ de largo por $0.70 \mathrm{~m}$ de ancho y parece corresponder a una antigua estructura habitacional elaborada con piedras cementadas con algas, como se suele observar en la estratigrafía de los sitios atribuidos a Paracas Necrópolis (Engel 1966: 160; Tello y Mejía Xesspe 1979: 254). Entre otros artefactos, los fardos estaban cubiertos por dos costillas de ballena, cinco esteras de fibra vegetal y una piel de lobo marino curtida ${ }^{4}$ (Archivo de Engel, Lima [MUNABA], 14a-VI-3 Tumbas (B) f. 91: 113-114). Estas ofrendas son comunes en los sitios de Cabezas Largas y de Wari Kayan - llamado también Cerro Colorado por el color rojizo de sus lomas - localizado a poca distancia hacia el sur (Tello 1929: 680, 1959: 56; Tello y Mejía Xesspe 1979: 78 y 297).

La tumba T.27 contenía siete fardos funerarios (Figura 3), seis adultos - confirmada la presencia de tres hombres y dos mujeres - y dos niños. De acuerdo con las interpretaciones de Bischof (Archivo de Engel, Lima [MUNABA] 14a-VI-3 Tumbas (B) f. 91: 136-145), los Fardos I, II, III y VII contenían un adulto, los Fardos V y VI llevaban cada uno un niño y un adulto enfardelados separadamente ${ }^{5}$, y ningún individuo fue registrado al interior del Fardo IV. Por lo mencionado, una de las publicaciones de Engel hace referencia a la tumba con el número equivocado de individuos (Engel 1966:

2. El primer código representa una versión antigua del segundo, siendo la segunda versión el único código publicado por Engel.

3. Según la información recopilada en el archivo de Engel, el código completo de la tumba sería 104 AG/14a-VI-3 U.III SC.V T.27.

4. Cuatro esteras se encuentran en las colecciones del MUNABA y la otra en custodia en el MRI. Una de las costillas de ballena fue traslada al antiguo Museo de Paracas (Archivo de Engel, Lima [MUNABA] Catálogo Paracas: 1) pero no fue ubicada hasta la fecha, tal vez por un problema de rótulo en la pieza. Por otro lado, es probable que la piel de lobo marino curtida fuese desechada por su estado de conservación.

5. Los niños fueron encontrados en bultos superiores, reforzando la idea de Bischof de que podría tratarse de entierros segundarios (Archivo de Engel, Lima [MUNABA] 14a-VI-3 Tumbas (B) f. 91: 139). 




Figura 3: Dibujo de perfil de la tumba T.27 de Cabezas Largas (Lévy Contreras y Román Aquino 2018: 42, Img. 03).

175) y describe más adelante el mismo contexto con el número de individuos correcto (Engel 1966: 204). Como lo explica Paul (1991: 26), aunque los trabajos de Engel son importantes para la región estudiada, estos descuidos o errores revelan que la presentación de los datos recuperados es imprecisa. Es tal vez por este motivo que los aportes científicos de Engel son criticados en la arqueología peruana (Velarde 2002-2003).

Los entierros descubiertos en la tumba T.27 de Cabezas Largas presentan materiales atribuidos al estilo Paracas Necrópolis-Topará (fases Ocucaje 8, 9 y 10) relacionados con el final del Horizonte Temprano en la región. Un fechado radiocarbónico tomado en muestras de carbón y restos botánicos $^{6}$, con fecha $2060 \pm 170$ A.P. (Engel 1991: 56), confirma esta filiación estilística que coincide con el Periodo II de Engel (1966: 171; 1991: 94-96). Por ende, los textiles del contexto estudiado pueden ser comparados con los materiales hallados por Tello y Mejía Xesspe en los sitios de Cabezas Largas y de Wari Kayan (Tello 1929, 1959; Tello y Mejía Xesspe 1979, Archivo Tello 2009, 2012; MNAAHP 2013).

\section{Los textiles paracas analizados en la muestra}

En la muestra estudiada, 96 textiles fueron registrados por Engel y su equipo: 53 textiles pertenecen a la colección del MUNABA, tres de ellos siguen en exposición en el MSP, 22 se encuentran en los depósitos del MRI y una pieza fue robada $^{7}$. Por ende, 17 materiales no fueron localizados hasta la fecha. Resumiendo los datos obtenidos en esta investigación, se registraron hasta la fecha:

- Elementos de tocado en fibra de algodón o de camélido elaborados en sprang o torsal doble.

- Bandas anudadas con flecos de urdimbre en fibra de camélido (llautos).

- Cordones anillados de forma tubular en fibra de camélido decorados con plumas.

- Mantos y paños de tela llana en fibra de algodón con decoración bordada en fibra de camélido.

- Mantos de tela llana en fibra de algodón con decoración pintada o recamados con plumas.

- Túnicas de tela llana en fibra de algodón decoradas con flecos.

- Mantos de tela llana en fibra de algodón o de camélido decorados con zonas de urdimbres cruzadas creando ojales

- Mantos y túnicas en fibra de algodón decorados con bandas tejidas con urdimbres suplementarias en fibra de camélido.

- Bolsas de tejido abierto en fibra de algodón.

- Hondas en fibra vegetal trenzada decoradas con borlas en fibra de algodón.

Para demostrar la importancia de la tumba T.27 de Cabezas Largas, se presentará a continuación una selección de los principales hallazgos textiles del contexto haciendo énfasis en el tipo de material o vestimenta elaborado, su ubicación, como ofrendas exteriores o asociadas a los fardos funerarios, sus características técnicas y, si posible, su contenido iconográfico. Se identificarán las piezas por su código completo ${ }^{8}$.

\section{Los plumarios:}

Dos abanicos de plumas fueron colocados encima del Fardo III (Archivo de Engel, Lima [MUNABA] 14aVI-3 Tumbas (B) f. 91: 114). Uno de ellos se ubica en los

6. El fechado NZ-1127/2 (no cal.) fue realizado en 1961 a partir de una muestra tomada por Engel y Bischof en el Fardo V (Archivo de Engel, Lima (MUNABA), Fechados RC. 14 por Sitio: Cuaderno 7). Su resultado fue publicado como una referencia para discutir el inicio del Horizonte Temprano en la costa sur del Perú (Ravines 1982: 170-171; Burger 1988: 109, Tabla 1).

7. Gracias a la ayuda de Rubén García Soto (comunicación personal, 2018), se pudo confirmar el robo del material en el antiguo Museo de Paracas en 1992.

8. Para el MUNABA, estos códigos corresponden a los números de inventario dados por Engel. Para el MSP, aparecen los códigos de propietario seguidos entre corchetes de los números de inventarios originales de las piezas. Se precisará por escrito si los materiales están en custodia en el MRI. 

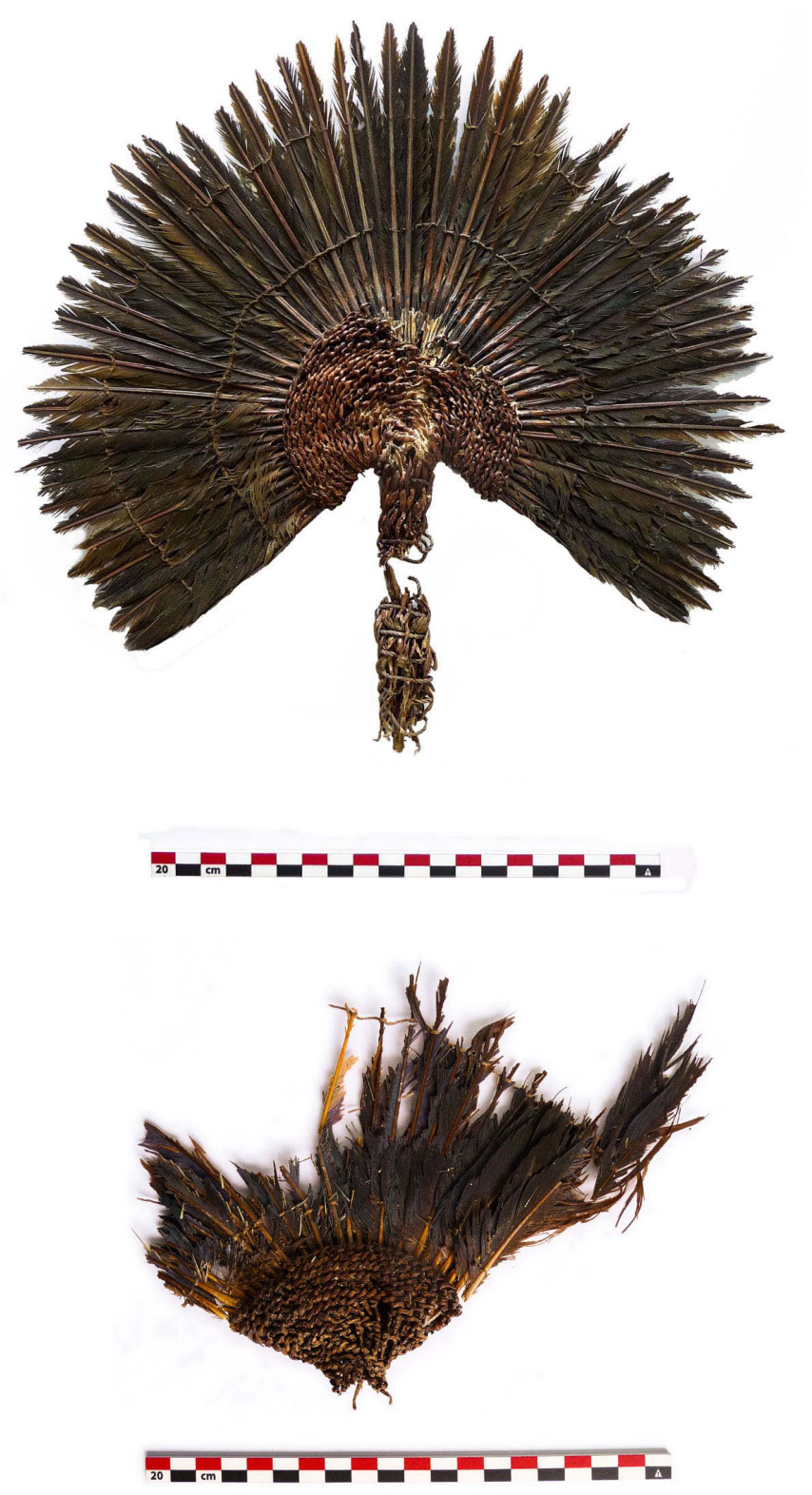

Figuras 4 A y B: Los abanicos MSP-0114-09 [0.2293-V.244] y V.245 en su vista posterior (Fotografías: Jessica Lévy Contreras, cortesía MRI).

depósitos del MRI (MSP-0114-o9 [0.2293-V.244]) y el otro ejemplar en el MUNABA (V.245). Por lo tanto, sólo la primera pieza se encuentra en estado de conservación regular. Se trata de un abanico de fibra vegetal decorado con plumas de color marrón oscuro de dimensiones generales $27.3 \mathrm{~cm}$ de alto por $29 \mathrm{~cm}$ de ancho (Figura $4 \mathrm{~A}$ ). El cálamo de las plumas está entrelazado a la estructura de fibra vegetal compuesta por cabos de junco de 2 a $2.5 \mathrm{~mm}$ de grosor. En la parte central de la estructura, de forma semicircular y de diámetro $9.2 \mathrm{~cm}$, se observa residuos de pegamento de color beige indicando una conservación o un montaje anterior del material. La estructura de fibra vegetal termina por dos fragmentos de mango amarrados hasta su base con un cordón de algodón beige de estructura $\mathrm{Z}(2 \mathrm{~s}(4 \mathrm{z}))^{9}, 5 \mathrm{O}^{\circ}$ de torsión y $2 \mathrm{~mm}$ de grosor para dar más solidez a la pieza. Las dimensiones del mango son de $17.2 \mathrm{~cm}$ de alto por $2.5 \mathrm{~cm}$ de ancho y tiene un grosor de $1.4 \mathrm{~cm}$. Las plumas, con dimensiones aproximadas de 14.5 $\mathrm{cm}$ de largo por $1.5 \mathrm{~cm}$ de ancho, fueron atadas de manera regular en dos partes de su raquis con un hilo en fibra de algodón de estructura $Z(2 \mathrm{~s}), 40^{\circ}$ de torsión y $1 \mathrm{~mm}$ de grosor. Por sus dimensiones, las plumas parecen provenir de las alas de un ave costeña. Un fragmento del segundo abanico fue conservado y presenta las mismas características técnicas. De dimensiones $21 \mathrm{~cm}$ de alto por $21.5 \mathrm{~cm}$ de ancho y $1.7 \mathrm{~cm}$ de grosor, sus plumas de color azul pertenecen a la especie de guacamayo Ara ararauna (Figura 4 B). Por lo visto, los abanicos MSP-0114-09 [0.2293-V.244]) y V.245 se asemejan a los ejemplares encontrados en Wari Kayan (Tello y Mejía Xesspe 1979: 478).

Relacionados con las ofrendas del Fardo VII, dos adornos de plumas conservados en el MUNABA destacan por su confección (V.292 A y B). De forma circular, las piezas fueron elaboradas con plumas de color beige amarillento y negro atadas en su raquis con un hilo en fibra algodón de estructura $\mathrm{S}(2 \mathrm{z}), 50^{\circ}$ de torsión y $0.5 \mathrm{~mm}$ de grosor de manera regular. Las plumas, con dimensiones aproximadas de 8 a $3 \mathrm{~cm}$ de largo por 3 a $1.5 \mathrm{~cm}$ de ancho, fueron colocadas en alternancia de color y sus puntas cortadas para acentuar su decoración en círculos concéntricos. Gracias a las imágenes obtenidas con microscopio digital portátil Dino-Lite, se pudo observar en el material V.292 A que los cálamos de las plumas fueron doblados en dos y amarrados con un hilo en fibra de algodón de estructura $\mathrm{S}(2 \mathrm{z}), 6 \mathrm{o}^{\circ}$ de torsión y $1 \mathrm{~mm}$ de grosor a un elemento de madera tallado en punta y pulido de aproximadamente $9 \mathrm{~cm}$ de largo por $3 \mathrm{~mm}$ de grosor. La punta de madera, semejante a la forma de un tupu, sugiere que el adorno fuese un elemento de tocado. Las dimensiones generales de la pieza son de $21.5 \mathrm{~cm}$ de alto por $20.2 \mathrm{~cm}$ de ancho y $1.8 \mathrm{~cm}$ de grosor (Figura $5 \mathrm{~A}$ ). El adorno V.292 B, en estado fragmentario y con manchas de carbonización, tiene rasgos técnicos y decorativos similares. Sin embargo, este se diferencia del otro adorno por estar asociado a dos borlas de plumas de color beige amarillento y negro atadas a un cabo de junco de estructura $\mathrm{Z}(2 \mathrm{~s}), 6 \mathrm{o}^{\circ}$ de torsión y $4 \mathrm{~mm}$ de grosor con un hilo de algodón de estructura $\mathrm{S}(2 \mathrm{z}), 50^{\circ}$ de torsión y $0.5 \mathrm{~mm}$ de grosor. Se puede pensar que las borlas decoraban originalmente el contorno 

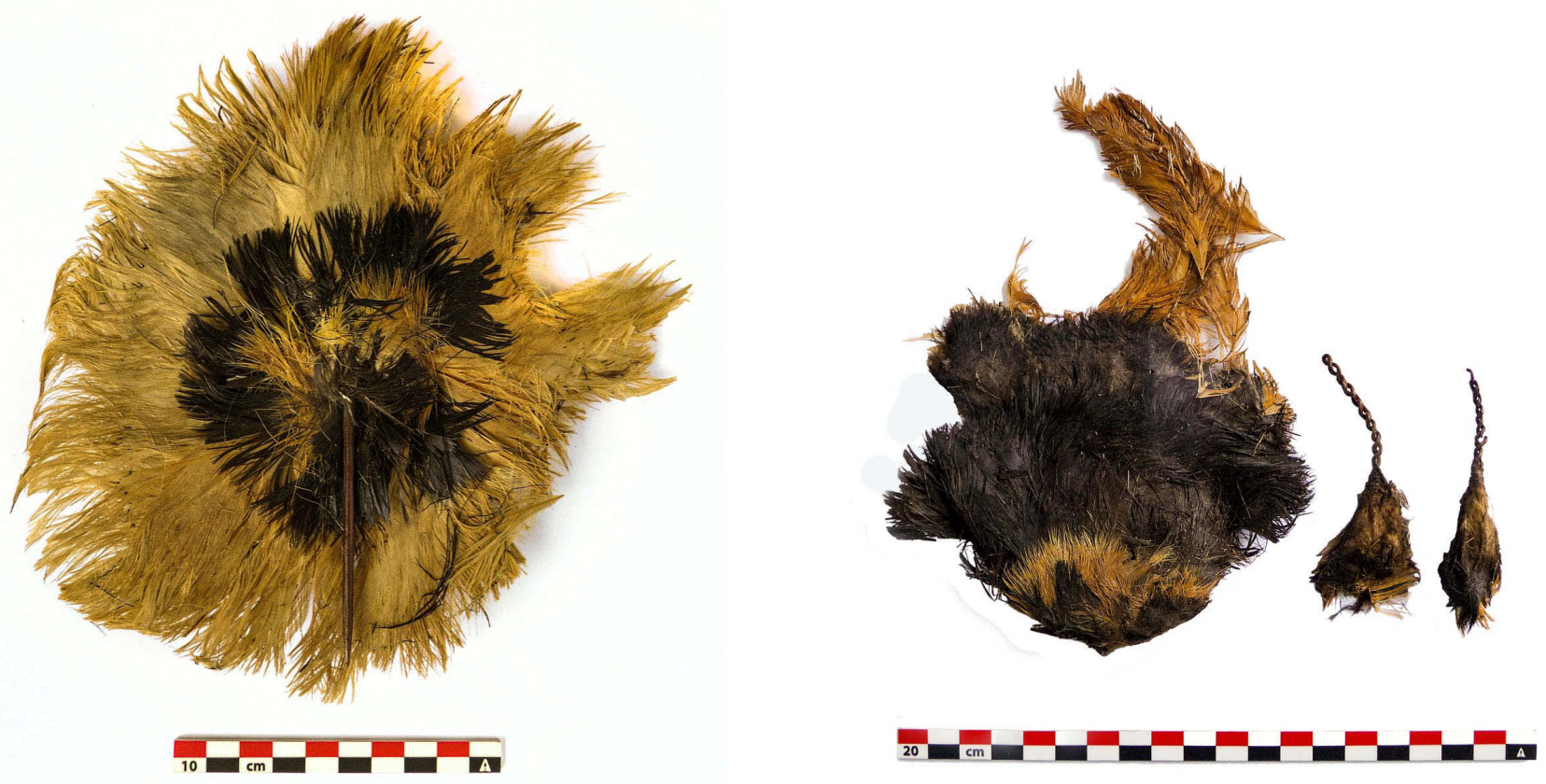

Figuras 5 A y B: Los adornos de plumas V.292 A y V.292 B (Fotografía: Jessica Lévy Contreras).

de la pieza. Las dimensiones generales del artefacto son de $18 \mathrm{~cm}$ de alto por $14 \mathrm{~cm}$ de ancho y tiene un grosor de 2 $\mathrm{cm}$. Sus borlas miden $9 \mathrm{~cm}$ de alto por $3.5 \mathrm{~cm}$ de ancho y $8.2 \mathrm{~cm}$ por $2.3 \mathrm{~cm}$ de ancho. Ambas tienen $8 \mathrm{~mm}$ de grosor (Figura 5 B). El tamaño de las plumas varía entre 7 y $3 \mathrm{~cm}$ de alto por 2 a $3 \mathrm{~cm}$ de ancho y parecen provenir de diferentes aves costeñas ${ }^{10}$. Al parecer, los adornos V.292 A y B son únicos por su forma y su técnica.

Asimismo, se mencionan en los registros gráficos de Engel y Bischof el hallazgo de mantos recamados con plumas en los Fardos IV, V Individuo B y VII (Archivo de Engel, Lima [MUNABA] 14a-VI-3 Tumbas (B) f. 91: 133, 138, 142, 156, 158 y 160). Aunque dichos materiales no fueron ubicados hasta la fecha, a excepción de un fragmento conservado en los depósitos del MRI asociado al Fardo VII (MSP-0391-02 [V.309] $)^{11}$, algunas fotografías en blanco y negro permiten observar sus características. Por ejemplo, existe una toma fotográfica del manto plumario encontrado durante el desenfardelamiento del Fardo V Individuo B (Figura 6). Cruzando los datos de la documentación recopilada, podemos afirmar que se trataba de un manto en fibra de algodón recamado con plumas de color amarillo y negro, las últimas decorando los bordes de la tela a manera de banda ancha. La pieza corresponde a la primera capa de envoltorio del individuo, tras haber retirado un manto de tela llana al exterior

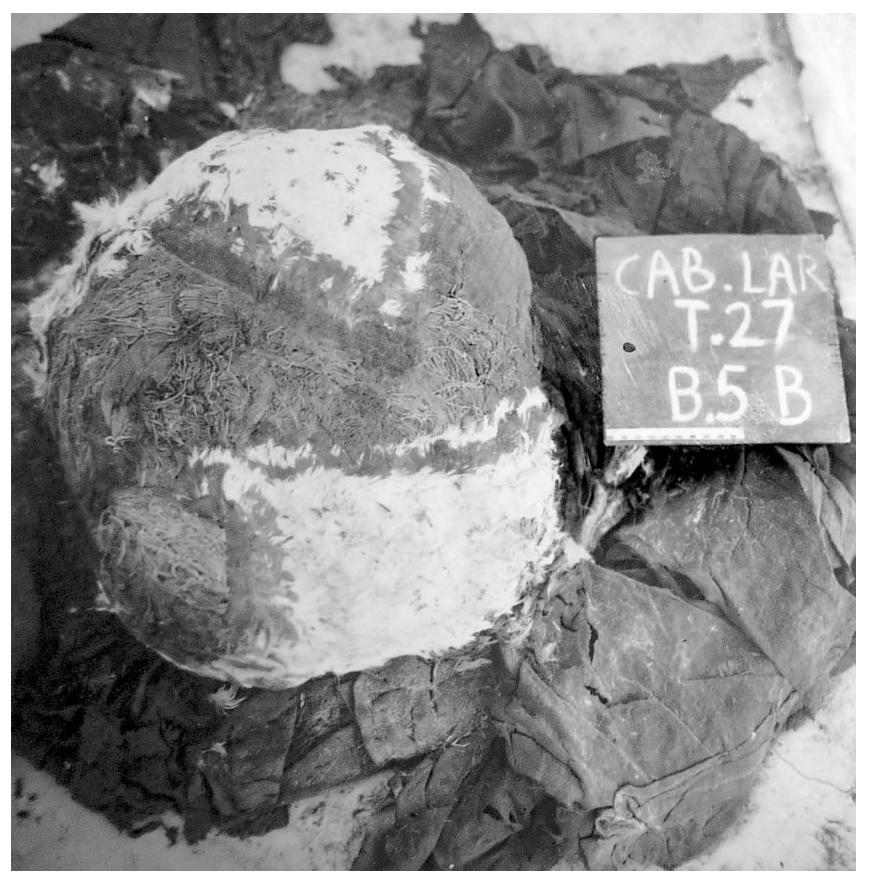

Figura 6: El manto plumario MSP-0391-02 [V.309] durante el desenfardelamiento del Fardo V Individuo B (Archivo de Engel, Lima [MUNABA] 14a-VI-3 Tumbas (B) f. 91: 85).

del fardo (Archivo de Engel, Lima [MUNABA] 14a-VI-3 Tumbas (B): f. 91: 138 y 158). 

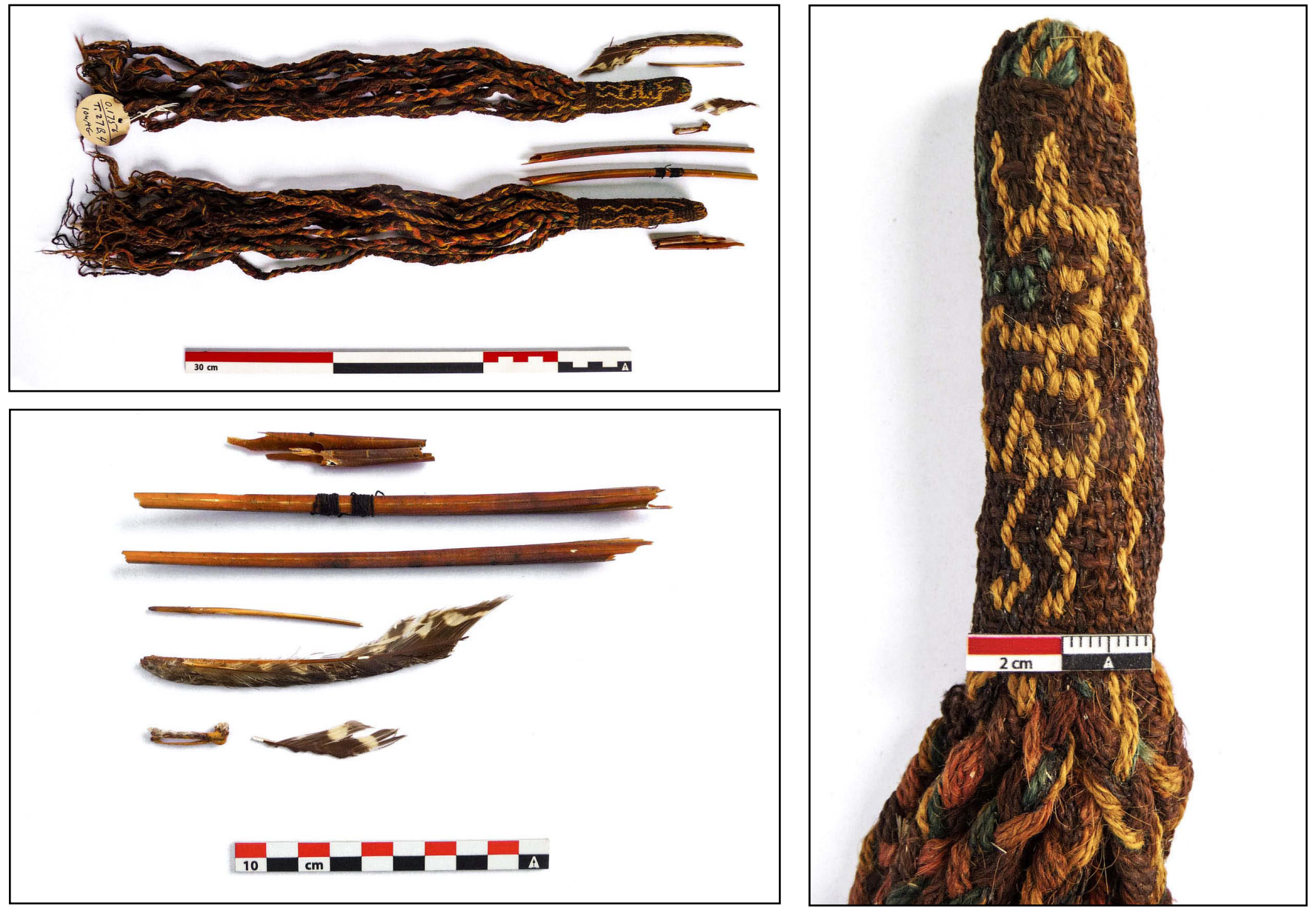

Figuras 7 A, B y C: Las borlas o.1756, detalle de su decoración bordada y plumas de halcón (Fotografías: Jessica Lévy Contreras).

Los materiales compuestos:

Varios materiales compuestos por elementos de diferente naturaleza fueron descubiertos en la tumba T.27. Relacionada con las ofrendas del Fardo IV, la pieza 0.1756 representa a dos borlas en fibra de camélido crudo y teñido en diversos colores que combinan diferentes elementos. Se trata de uno de los materiales del contexto mejores conservados en el MUNABA. Confeccionadas a partir de 15 y 14 cordones trenzados de color marrón, beige ocre, rojo y azul verdoso, las borlas fueron envueltas de forma tubular en su parte superior por una tela llana de color marrón con decoración bordada de color beige ocre y azul verdoso y cosida en su borde de urdimbre con puntadas diagonales de color marrón (Figura 7 A). Las trenzas, de $8 \mathrm{~mm}$ de ancho, fueron realizadas con hilos de estructura $\mathrm{S}(2 \mathrm{z}), 45^{\circ}$ de torsión y $1 \mathrm{~mm}$ de grosor. La tela, con 5 elementos de urdimbre por 4 elementos de trama en un centímetro cuadrado, tiene hilos de estructura $\mathrm{S}(2 \mathrm{z}), 50^{\circ}$ de torsión y $1 \mathrm{~mm}$ de grosor. Los hilos de la decoración bordada, que muestra a dos personajes antropomorfos representados de perfil sosteniendo en una de sus manos un atributo y de cuya cabeza sale una línea en zigzag a manera de serpiente, poseen las mismas características que los hilos de los cordones trenzados (Figura $7 \mathbf{B}$ ). La parte tubular mide para cada borla $8.8 \mathrm{~cm}$ de largo por $2.2 \mathrm{~cm}$ de ancho y $7.2 \mathrm{~cm}$ de largo por $2.3 \mathrm{~cm}$ de ancho. Por último, la puntada diagonal tiene rasgos similares a los elementos de la tela llana. Varios fragmentos de plumas de halcón, atadas en su raquis con un hilo en fibra de algodón ${ }^{12}$ de estructura $\mathrm{S}(2 \mathrm{z}), 60^{\circ}$ de torsión y $0.5 \mathrm{~mm}$ de grosor, fueron recuperados junto con las borlas (Figura 7 C). Gracias al registro fotográfico original de la pieza (Archivo de Engel, Lima [MUNABA] Cuaderno $\mathrm{N}^{\circ}$ 5, Negativo: F.3570), se supone que dichos elementos estaban amarrados a la extremidad superior de las borlas. Las dimensiones generales para cada artefacto son de $45.2 \mathrm{~cm}$ de largo por $6.5 \mathrm{~cm}$ de ancho y $43.8 \mathrm{~cm}$ de largo por $6.3 \mathrm{~cm}$ de ancho. 



Figuras 8 A y B: Detalle de la piel de puma MSP-oo93-16 [V.269] en su estado de conservación actual y fotografía original de la pieza (Fotografía: Jessica Lévy Contreras; Archivo de Engel, Lima [MUNABA] Caja No 1 , Tipología Varios: Ficha V.269).

La piel de puma MSP-oo93-16 [V.269], hallada entre dos capas de envoltorio del Fardo VII (Archivo de Engel, Lima [MUNABA] 14a-VI-3 Tumbas (B) f. 91: 160), fue intervenida en 2016 para su exposición en el MSP. Si bien la pieza tiene hoy un aspecto muy fragmentario, esta fue curtida, perforada y cosida antes de ser depositada como ofrenda. La cabeza del puma (Puma concolor), puesta en vista frontal, conserva cartílagos en las orejas y la nariz.
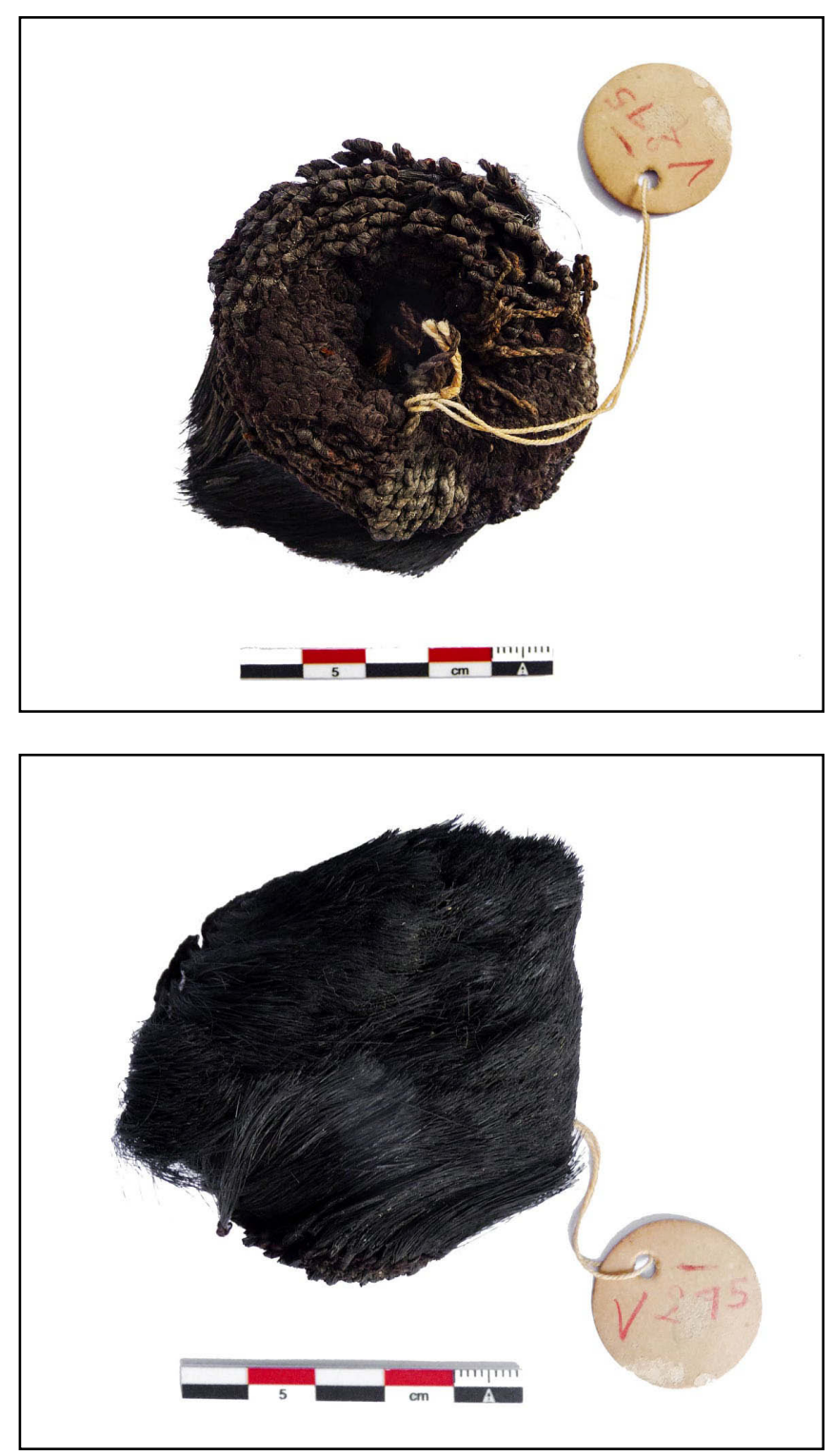

Figuras 9 A y B: Artefacto V.275-W.275 A en su vista anterior y posterior (Fotografías: Jessica Lévy Contreras).

Su boca fue cosida con un hilo en fibra de camélido de color marrón de estructura $\mathrm{S}(2 \mathrm{z})$ a una trenza en fibra de camélido de color marrón con elementos similares ${ }^{13}$. La trenza, que termina con nudo y flecos largos en sus extremidades, parece representar el bigote que el felino tenía en vida (Figura 8 A). Se observa también puntadas irregulares con restos de hilo en fibra de camélido de color marrón de estructura $\mathrm{S}(2 \mathrm{z})$ en la parte inferior del material. No obstante, es importante mencionar que el estado de conservación actual de la pieza no coincide con el registro fotográfico de Engel. Una flecadura independiente, 
probablemente cosida a la trenza, cubría originalmente la parte inferior de la boca hasta el cuello del animal (Figura 8 B). Este elemento pudo servir para resaltar los rasgos faciales del felino y/o su aspecto simbólico. Por ende, la piel de puma de la tumba T.27 de Cabezas Largas no parece tener equivalentes en los Andes centrales para este periodo ${ }^{14}$. Sus medidas aproximadas son de $92 \mathrm{~cm}$ de alto por $82 \mathrm{~cm}$ de ancho.

Un curioso artefacto compuesto por cabello, fibra vegetal y fibra de algodón fue encontrado en el ajuar del Fardo I (Archivo de Engel, Lima [MUNABA] 14a-VI-3 Tumbas (B) f. 91: 92). Conservada en el MUNABA, la pieza V.275-W.275 A fue elaborada con mechas de cabello de $3 \mathrm{~cm}$ de alto anudadas entre sí a un cordón de junco de estructura $\mathrm{S}(2 \mathrm{z})$, $45^{\circ}$ de torsión y $1 \mathrm{~mm}$ de grosor. Las mechas fueron atadas de forma concéntrica para formar la estructura del adorno. Asimismo, la parte superior del material presenta un cordón en fibra de algodón de color beige ocre de estructura $\mathrm{S}(2 \mathrm{z}), 50^{\circ}$ de torsión y $0.5 \mathrm{~mm}$ de grosor con nudos. Dicho elemento pudo servir para dar más solidez a la estructura y/o decorarla (Figuras 9 A y B). De dimensiones $6.8 \mathrm{~cm}$ de largo por $5.2 \mathrm{~cm}$ de ancho, el artefacto fue descrito como "escobilla" (Archivo de Engel, Lima [MUNABA] Caja $\mathrm{N}^{\circ}$, Número Varios: Ficha V.275 A; Caja ${ }^{\circ}$ 3, Tipología Madera: Ficha W.275 A) mientras que otro ejemplar similar, encontrado en las ofrendas del Fardo VII ${ }^{15}$, fue interpretado como "brocha" (Archivo de Engel, Lima [MUNABA] Caja Nº 1 , Número Varios: Ficha V.295) o "peine" (Archivo de Engel Caja $\mathrm{N}^{\circ} 3$, Tipología Madera: Ficha W.295). En todo caso, no cabe duda de que se trata de una pieza particular.

Los textiles y los elementos de tocado:

El manto 0.1862 fue descubierto entre las capas 6 y 8 del Fardo VII, como lo demuestra una fotografía del individuo en proceso de desenfardelamiento (Figura 10 A). Aunque sólo se conservaron fragmentos carbonizados de la pieza en el MUNABA, consolidados con pegamento e hilos en un soporte de papel acartonado, se observa restos de tela llana en fibra de algodón con decoración bordada en fibra de camélido crudo y teñido en diversos colores. Los hilos de la tela tienen una estructura $\mathrm{S}(2 \mathrm{z}), 6 \mathrm{o}^{\circ}$ de torsión y $0.5 \mathrm{~mm}$ de grosor, mientras que los hilos de la decoración bordada tienen una estructura $\mathrm{S}(2 \mathrm{z}), 50^{\circ}$ de torsión y $1 \mathrm{~mm}$ de grosor. La decoración bordada, de color beige ocre, marrón, gris y rojo, muestra personajes antropomorfos representados de frente con lagrimales de halcón en su rostro, un felino visto de perfil al interior de su cuerpo y apéndices que
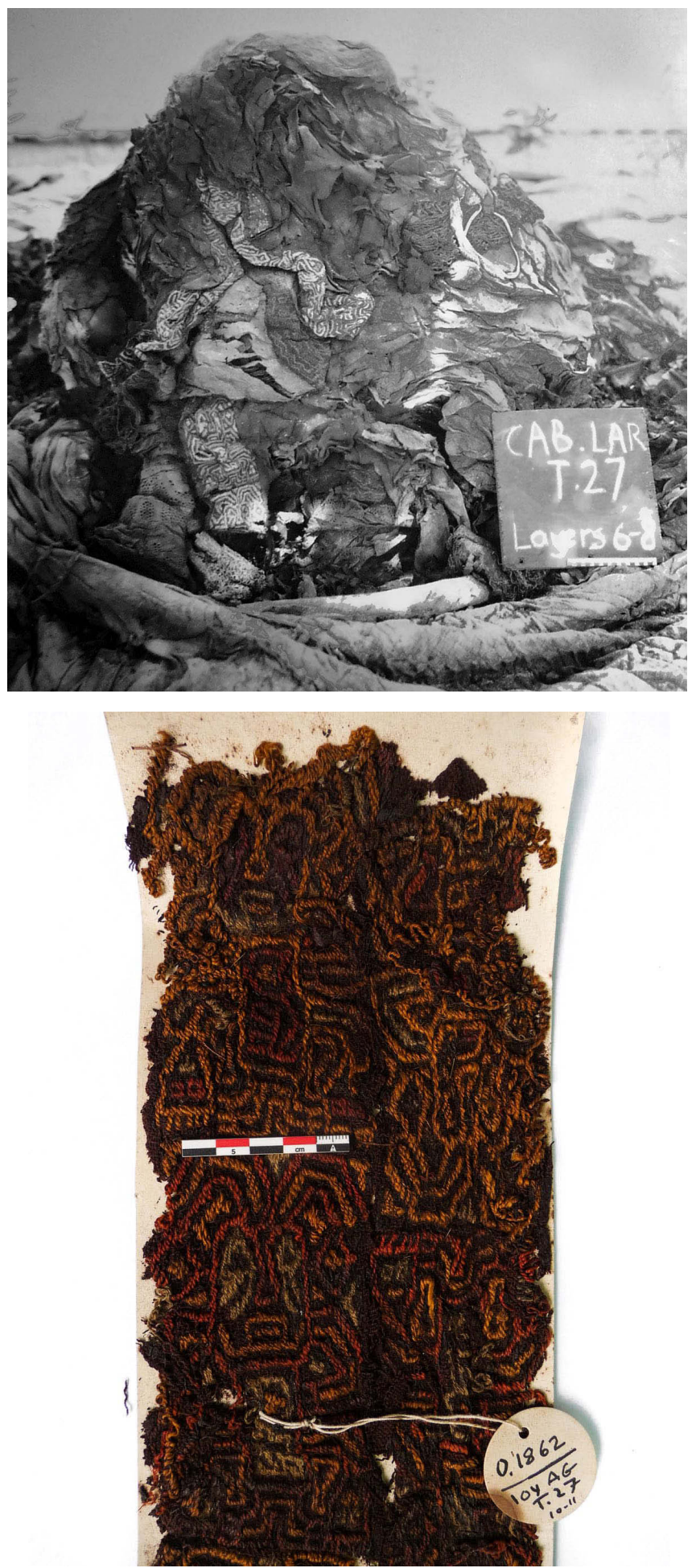

Figuras 10 A y B: Vista del manto 0.1862 entre las capas 6 y 8 del Fardo VII, detalle de su decoración bordada conservada en el MUNABA (Archivo de Engel, Lima [MUNABA] 14a-VI-3 Tumbas (B) f. 91: 88; Fotografía: Jessica Lévy Contreras).

14. A manera de comparación, una máscara de puma procedente del valle de Azapa y asociada con el Periodo Medio (500-10oo d.C.) fue encontrada en Arica, Chile. Dicha pieza pertenece a la colección del Museo Arqueológico San Miguel de Azapa de la Universidad de Tarapacá (Cf. Portada de Chungara: Revista de Antropología Chilena, Vol. 50 (1) 2018).

15. Solamente se conserva un dibujo de la pieza en su ficha de inventario. 

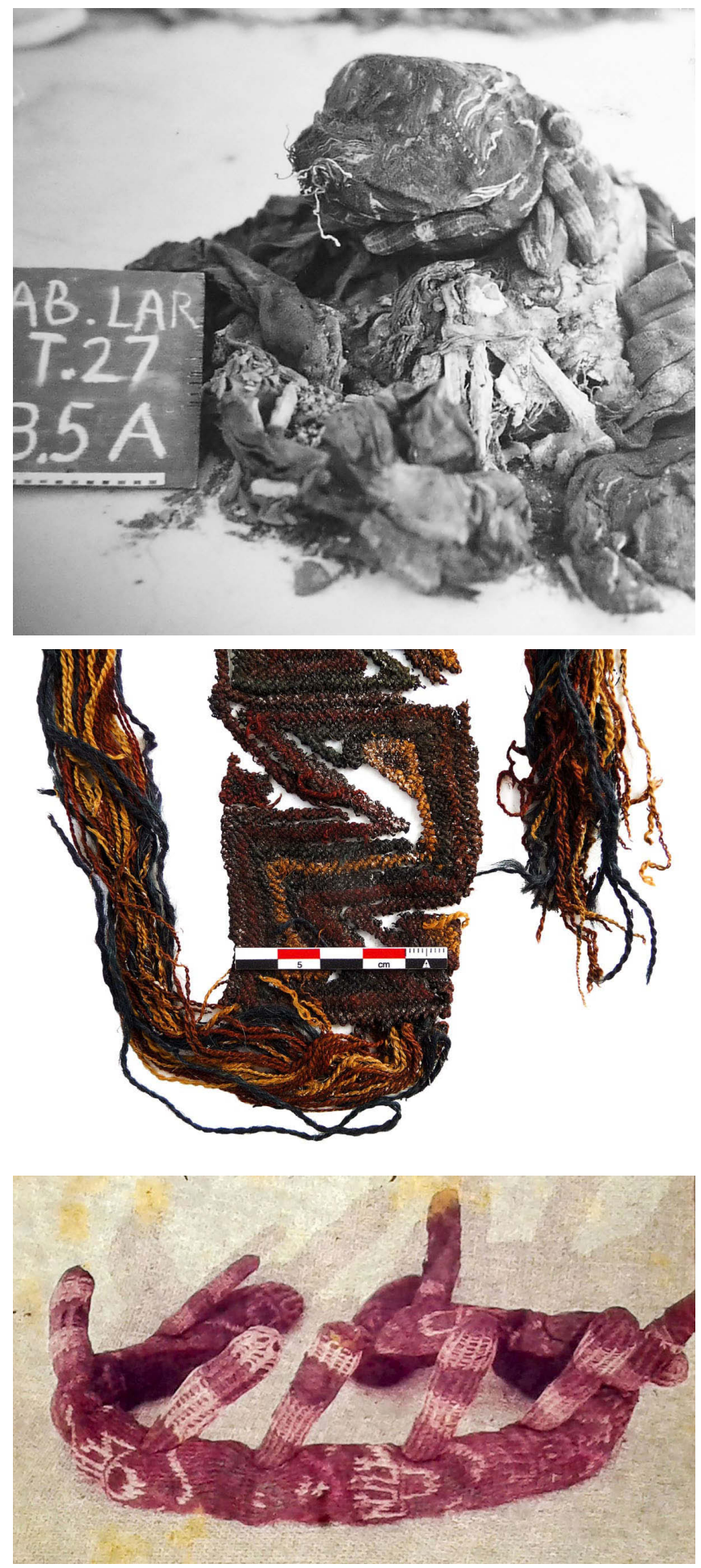

Figuras 11 A, B y C: Registro fotográfico de los materiales 0.1706 y 0.2015 en la cabeza del Fardo V Individuo A, detalle de la banda anudada 0.1706 y diapositiva a color del tocado 0.2015 (Archivo de Engel, Lima [MUNABA 14a-VI-3 Tumbas (B) f. 91: 85; Fotografía, Jessica Lévy Contreras; Caja $\mathrm{N}^{\circ} 3$, Tipología Tejidos: Ficha 0.2015). brotan de su cabeza y cintura de cuyas terminaciones nacen cabezas-trofeo (Figura 10 B). Por el estado de conservación actual del manto, se estima que la decoración bordada corresponde al borde de urdimbre y mide $7 \mathrm{~cm}$ de ancho. Las dimensiones originales de la pieza no fueron registradas en las fichas de inventario del material (Archivo de Engel, Lima [MUNABA] Caja Nº3, Tipología Tejidos: Ficha o.1862; Caja $\mathrm{N}^{\circ} 2$, Colección Básica Tejidos: Ficha 0.1862; Caja 14a-VI-3 T.27 Paracas, Análisis Textil Sitios: Ficha 0.1862). Se trata del fragmento de manto bordado en mejor estado de conservación estudiado en la muestra hasta la fecha.

De acuerdo con el registro fotográfico del Fardo V Individuo A (Archivo de Engel, Lima [MUNABA] 14a-VI-3 Tumba (B) f. 91: 85 y 92; Cuaderno $\mathrm{N}^{\circ} 1$, Negativos: F.686 y 688), la cabeza de un niño estaba originalmente decorada por dos tocados (Figura 11 A). Si bien la pieza 0.1706 se encuentra muy deteriorada por su carbonización, esta fue analizada con microscopio digital portátil para determinar su estructura y colores originales en el MUNABA. Realizada con hilos de camélido crudo y teñido en diversos colores de estructura $\mathrm{S}(2 \mathrm{z}), 50^{\circ}$ de torsión y $1 \mathrm{~mm}$ de grosor, se trata de una banda anudada con flecos de urdimbres decorada con diseños geométricos de color beige ocre, marrón, negro, rojo y azul oscuro (Figura 11 B). El material tiene dimensiones aproximadas de $1.05 \mathrm{~m}$ de largo por $6.3 \mathrm{~cm}$ de ancho (Archivo de Engel, Lima [MUNABA] Caja $\mathrm{N}^{\circ} 3$, Tipología Tejidos: Ficha 0.1706; Caja $\mathrm{N}^{\circ}$ 1, Colección Básica Tejidos: Ficha 0.1706; Caja 14a-VI-3 T.27 Paracas, Análisis Textil Sitios: Ficha 0.1706). Por otro lado, el tocado 0.2015 no fue ubicado hasta la fecha. Gracias al registro gráfico y fotográfico de la pieza (Archivo de Engel, Lima [MUNABA] Caja $\mathrm{N}^{\circ} 3$, Tipología Tejidos: Ficha 0.2015; Caja $\mathrm{N}^{\circ} 2$, Colección Básica Tejidos: Ficha 0.2015; Caja 14a-VI-3 T.27 Paracas, Análisis Textil Sitios: Ficha 0.2015), podemos observar que el material se compone de un cordón anillado de forma tubular decorado con nueve puntas en anillado cruzado $^{16}$, probablemente rellenadas con fibra de algodón y cosidas de forma radiante en la parte superior del cordón. La pieza muestra además una decoración compleja con aves bicéfalas y diseños geométricos creada con hilos en fibra de camélido crudo y teñido en diversos colores (Figura 11 C). Es la primera vez que se registra este tipo de tocado en la cultura Paracas.

\section{El manto pintado MSP-0043-02 [0.1316]:}

El Fardo VII, sin duda uno de los individuos más importantes de la tumba por su ajuar funerario, contenía por lo menos 13 capas de envoltorio y cerca de 80 ofrendas (Archivo de Engel, Lima [MUNABA] Tumbas (B) f. 91: 142-145,

16. Se encontraron fragmentos de un tocado similar decorado con borlas de plumas amarillas asociado al Fardo II (V. 290). Por lo tanto, el registro gráfico de Engel y Bischof no permite confirmar si la pieza pertenece al ajuar del individuo. 




Figura 12: El manto pintado MSP-0043-02 [0.1316] (Fotografía: cortesía, Luis Alberto Peña Callirgos).

159-161). Aunque solamente 42 artefactos fueron identificados y ubicados entre las colecciones del MUNABA y del MSP-MRI, sabemos que el manto pintado MSP-0043-02 [0.1306] fue descubierto en los primeras capas de envoltorio del fardo, posiblemente en la capa 5 . Por su carácter excepcional, se trata del material más documentado ${ }^{17}$ de la tumba T.27 del cual sólo un detalle fue publicado por Engel (1991: 102, Fig. 71). De dimensiones $2.60 \mathrm{~m}$ de largo por 1.56 $m$ de ancho, el manto se compone de dos paños de tela llana en fibra de algodón beige unidos en su borde de urdimbre con puntada diagonal. La tela tiene 13 elementos de urdimbre por 10 elementos de trama en un centímetro cuadro y fue elaborada con hilos de estructura $\mathrm{S}(2 \mathrm{z})$ cuya torsión varía entre $40^{\circ}$ y $45^{\circ}$ y grosor entre 0.5 y $1 \mathrm{~mm}$. La puntada fue realizada con un hilo en fibra de algodón beige de estructura $\mathrm{S}(2 \mathrm{z}), 45^{\circ}$ de torsión y $1.5 \mathrm{~mm}$ de grosor. Pintado con pigmentos naturales de color negro, el manto está decorado con ocho personajes antropo-zoomorfos representados de pie con la cara de frente y el cuerpo de perfil que alternan en sus posiciones (Figura 12). Estos se diferencian por su vestimenta, sus atributos de poder (cabezas-trofeo y flechas) y el número de sus apéndices serpentiformes, extraños brotes que sirven para transformar a un humano en un ser sobrenatural (Makowski 2000, 2017; Lévy Contreras 2017). Por sus características iconográficas, en particular por su rostro cordiforme con ojos redondos y boca sonriente, los personajes se relacionan con la figura del "Ser Oculado” cuya representación se vincula con la cerámica del valle de Ocucaje entre el final del Horizonte Temprano y el inicio del Periodo Intermedio Temprano (Menzel, Rowe y Dawson 1964; Dywer y Dwyer 1975; Massey 1986; Bachir Bacha y Llanos 2012; Carmichael 2016). El estado de conservación de la pieza sufrió por el montaje que esta recibió para su exposición en el antiguo Museo de Paracas, lo cual fue confirmado por la comparación de los documentos fotográficos de Engel con el estado actual del material (Lévy Contreras y Román Aquino 2018).

\section{Las “muñecas” de la tumba T.27:}

Denominadas como "muñecas" y asociadas a los Fardos III (0.2766), IV (0.2765) y V (0.2767), tres estructuras elaboradas con fibra de totora y decoradas con telas bordadas

17. Existe más de 6o documentos fotográficos del manto pintado (Archivo de Engel, Lima [MUNABA] 14a-VI-3 Tumbas (B) f. 91: 87, 88, 90, 93, 96 y 162; Cuaderno $\mathrm{N}^{\circ}$ 1, Negativos: F.703, 704 y 717-730; Cuaderno $\mathrm{N}^{\circ}$ 5, Negativos: F.3571, 3751, 3892 y 3895; Cuaderno $\mathrm{N}^{\circ} 8$, Negativos: F.639o-6393; Caja Nº2, Tipología Tejidos: Ficha 0.1316; Caja Nº 1, Colección Básica Tejidos: Ficha 0.1316; Caja 14a-VI-3 T.27 Paracas, Análisis Textil Sitios: Ficha 0.1316; Caja Fotos Tejidos: 0.1316; Caja Fotos Tejidos Textiles: 0.1316; Caja Tejidos Colecciones de Slides: o.1316). 

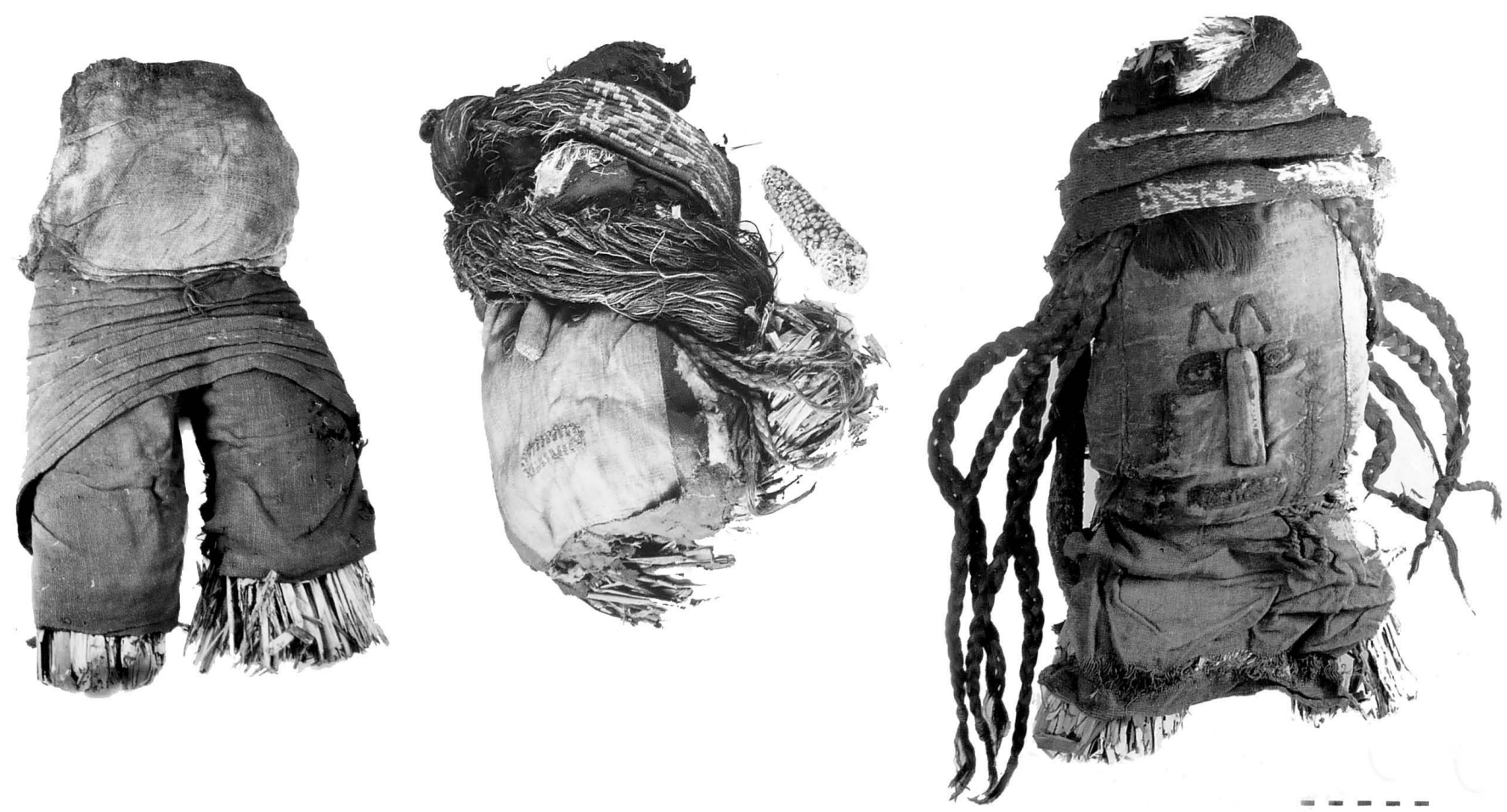

Figuras 13 A, B y C: Las "muñecas" 0.2766, 0.2765 y 0.2767 de la tumba T.27 de Cabezas Largas elaboradas con totora, tela bordada, cabello y decoradas con tocados (Archivo de Engel, Lima [MUNABA] Caja ${ }^{\circ}{ }^{\circ}$, Tipología Tejidos: Ficha o.2766; Análisis Textil Sitios: Ficha 0.2765; Caja $\mathrm{N}^{\circ}$ 5, Tipología Tejidos: Ficha 0.2767).

para simbolizar su rostro fueron colocadas como ofrendas al interior de cada fardo funerario (Archivo de Engel, Lima [MUNABA] 14a-VI-3 Tumbas (B) f. 91: 129, 137, 154, 156 y 157). Si bien se conservaron únicamente las fotografías originales de las piezas, puesto que una de ellas fue hurtada del antiguo Museo de Paracas y que las dos otras no fueron localizadas hasta la fecha, se puede observar sus detalles técnicos y decorativos para explicar la importancia de dichos materiales dentro del contexto estudiado. La "muñeca" 0.2766 , de $58 \mathrm{~cm}$ de alto, parece estar en proceso de elaboración (Figura 13 A). Su estructura de totora muestra una cabeza sin rostro y piernas largas arropadas con diferentes telas (Archivo de Engel, Lima [MUNABA] Caja $\mathrm{N}^{\circ} 5$, Tipología Tejidos: Ficha 0.2766; Caja $\mathrm{N}^{\circ}$, Colección Básica Tejidos: Ficha 0.2766; Caja 14a-VI-3 T.27 Paracas, Análisis Textil Sitios: Ficha 0.2766). La segunda "muñeca" 0.2765, de $20 \mathrm{~cm}$ de alto por $18 \mathrm{~cm}$ de ancho, representa una cabeza humana con trenzas de cabello llevando una banda anudada con flecos de urdimbre y cordones enrollados de forma tubular decorados con aves bicéfalas y plumas de color amarillo. Los elementos de su rostro, en particular sus ojos y su boca sonriente con dientes, fueron bordados con hilos en fibra de camélido sobre una tela llana en fibra de algodón (Archivo de Engel, Lima [MUNABA] Caja $\mathrm{N}^{\circ} 5$, Tipología Tejidos: Ficha 0.2765; Caja $\mathrm{N}^{\circ} 3$, Colección Básica Tejidos: Ficha 0.2765; Caja 14a-VI-3 T.27 Paracas, Análisis Textil Sitios: Ficha 0.2765 ). Su nariz, de forma tridimensional, pudo haber sido rellenada con fibra de algodón (Figura 13 B). Finalmente, la "muñeca" 0.2767 , de $45 \mathrm{~cm}$ de alto, es la más compleja de la muestra. Su estructura de totora, similar a la de la pieza 0.2766 , se conforma de una cabeza con dos piernas cortas. Estás últimas fueron recubiertas por una tela decorada con flecos a manera de prenda corta. Su cabeza, con cerquillo y trenzas de cabello, tiene como tocado un cordón anillado de forma tubular ${ }^{18}$ decorado con aves bicéfalas y plumas de color amarillo (Archivo de Engel, Lima [MUNABA] Caja ${ }^{\circ}$ 5, Tipología Tejidos: Ficha 0.2767; Caja $\mathrm{N}^{\circ} 3$, Colección Básica Tejidos: Ficha 0.2767). El rostro de la "muñeca" está figurado con diferentes elementos bordados con fibra de camélido crudo y teñido en diversos colores $^{19}$ : cejas de forma geométrica, ojos redondos con pupilas, dos bandas decoradas con bordes dentados a manera de

18. No se menciona el tipo de fibra utilizada en los cordones anillados de forma tubular, pero se supone, por la técnica empleada, que dichos elementos fueron confeccionados con fibra de camélido.

19. Los elementos de la pieza eran de color marrón, rojo y verde oscuro (Rubén García Soto, comunicación personal 2018). 
pinturas faciales o tatuajes y una boca sonriente con dientes. De forma tridimensional, su nariz está decorada además con una línea bordada (Figura 13 C). Debemos resaltar que la "muñeca" 0.2767 estaba originalmente atada con un cordón al cuerpo del individuo (Archivos de Engel, Lima [MUNABA] 14a-VI-3 Tumbas (B) f. 91: 156). De acuerdo con las descripciones de Bischof (Archivo de Engel, Lima [MUNABA] 14a-VI-3 Tumbas (B) f. 91: 137-138), el adulto relacionado con el Fardo V (Individuo B) puede ser de sexo femenino por su parafernalia ritual. El peinado de la "muñeca" podría respaldar este argumento. De esta manera, aunque las "muñecas" recuerden las falsas cabezas paracas del valle de Ocucaje (Dawson 1979), estos materiales podrían ser interpretados como réplicas o miniaturas de las personas enterradas dado que presentan los mismos peinados y/o elementos de tocado. Si bien este planteamiento sólo es factible para el Fardo V, ya que la "muñeca” del Fardo III está incompleta y que el Fardo IV no contiene cuerpo, no cabe duda que los peinados y los elementos de tocado que decoran sus cabezas son idénticos a los utilizados en la parafernalia ritual de los individuos de la tumba.

\section{Conclusiones}

Depositados como ofrendas rituales, los textiles paracas muestran patrones diacrónicos y diferencias en el estatus social de los individuos por su técnica de manufactura, su decoración y la distribución del tipo de prendas hallado en cada fardo funerario (Yacovleff y Muelle 1934; O’Neale 1942; Carrión Cachot 1949; King 1965; Tello y Mejía Xesspe 1979; Frame 1986; Paul 1990; Peters 1997). Por lo mencionado, los textiles fueron utilizados como soportes ideológicos para enfatizar relaciones de poder, el género y posiblemente la edad de los individuos (Peters 2000, 2011; Frame 2008; Peters y Tomasto-Cagigao 2017). Este argumento puede ser explicado por la construcción del fardo funerario que legitima el poder de varios grupos o linajes (Dwyer y Dwyer 1975). De esta manera, los textiles de la tumba T.27 de Cabezas Largas podrían indicar el alto estatus de los individuos, su parentesco y/o procedencia. La recurrencia de los tipos de vestimenta encontrados en cada fardo funerario, tanto como el acceso a diferentes materias primas y su preparación, muestran rituales mortuorios y elementos culturales comunes a la región.

Si bien faltan analizar aún algunos materiales descubiertos por Engel y su equipo en la tumba, los resultados preliminares obtenidos sobre los textiles del contexto ofrecen elementos inéditos para entender mejor la parafernalia ritual paracas en su fase tardía. En efecto, la mayoría de los artefactos presentan una iconografía cuyas características estilísticas difieren de las fases Ocucaje 9-10, salvo algunas excepciones como el manto pintado MSP-0043-02 [0.1316]. Es interesante notar que las figuras complejas relacionadas con la transición Paracas-Nasca, a saber la representación de seres antropo-zoomorfos que varían por su postura, sus atributos de poder y sus apéndices serpentiformes, generalmente figurados en las decoraciones bordadas de mantos importantes, son ausentes en la muestra estudiada.

Asimismo, varios textiles de la tumba T. 27 de Cabezas Largas no parecen tener equivalentes por su forma, técnica y/o tratamiento decorativo. Analizados en este ensayo (V.292 A-B, MSP-0093-16 [V.269], V.275-W.275 A, 0.2015, $0.2765,0.2766$ y 0.2767 ), estos materiales parecen ser propios del ajuar de la tumba reforzando la idea de que los individuos tuvieran lazos de parentesco y/o convivieran en la misma comunidad. A contrario, los otros textiles del contexto estudiado muestran técnicas, decoraciones y colores similares a los materiales "Cavernas" excavados por Tello y Mejía Xesppe en Wari Kayan, reforzando la idea de que dichos artefactos pudieran ser relacionados con una fase anterior (Ocucaje 8). Finalmente, sólo futuros aportes permitirán confirmar las hipótesis presentadas en esta investigación para resaltar los datos obtenidos por Engel y Bischof hace medio siglo en la región.

\section{Agradecimientos}

Quisiera agradecer al director del MUNABA, Julio César Alfaro Moreno, y los trabajadores de dicha institución, Paolo Zaragastúa López y Lucio Laura Aguirre, por su constante apoyo y ayuda durante esta investigación; Katherine Román Aquino sin la cual no hubiera empezando esta labor; Susana Arce Torres, directora del MRI, por haberme permitido revisar algunos materiales de la tumba en vista de la preparación de la segunda parte del proyecto; Ann $\mathrm{H}$. Peters por prestarme su microscopio digital portátil y ayudarme en la identificación de las estructuras textiles más complejas; Luis Alberto Peña Callirgos por su fotografía del manto pintado conservado en 2016; Rubén García Soto por las informaciones brindadas acerca de las colecciones del antiguo Museo de Paracas; y José Ochatoma Cabrera por editar las imágenes de la presente publicación.

\section{Referencias citadas}

Archivo Tello

2009 Paracas Cavernas. Cuaderno del Archivo Tello 7. Museo de Arqueología y Antropología, Universidad Nacional Mayor de San Marcos, Lima.

2012 Paracas Wari Kayan. Cuaderno del Archivo Tello 9. Museo de Arqueología y Antropología, Universidad Nacional Mayor de San Marcos, Lima. 
Bachir Bacha, Aïcha y Oscar Daniel Llanos Jacinto

2012 Arqueología e iconografía de los textiles Paracas descubiertos en Ánimas Altas, Ica, Perú. En Actas de las $V$ Jornadas Internacionales sobre Textiles Precolombinos, 29 noviembre - 1 diciembre 2010, pp. 211-230, Universidad Autónoma de Barcelona, Barcelona.

Burger, Richard L.

1988 Unity and Heterogeneity within the Chavín Horizon. En Peruvian Prehistory: An Overview of Pre-Inca and Inca Society, editado por Richard W. Keatinge, pp. 99144, Cambridge University Press, Cambridge.

Carmichael, Patrick H.

2016 Nasca Origins and Paracas Progenitors. Nawpa Pacha: Journal of Andean Archaeology 36(2): 53-94.

Carrión Cachot, Rebeca

1949 Paracas Cultural Elements. Corporación Nacional de Turismo, Lima.

Dawson, Lawrence E.

1979 Painted Cloth Mummy Masks of Ica. En The Junius B. Bird Pre-Columbian Textile Conference, May $19^{\text {th }}$ and $20^{\text {th }}$, 1973, editado por Ann P. Rowe, Elizabeth P. Benson and Anne-Louise Schaffer, pp. 83-104, The Textile Museum and Dumbarton Oaks Research Library and Collections, Trustees for Harvard University, Washington, DC.

Dwyer, Edward y Jane P. Dwyer

1975 Mortuary Patterns in a Peruvian South Coastal Tradition. En Death and Afterlife in Pre-Columbian America: A Conference at Dumbarton Oaks, October $27^{\text {th }}, 1973$, editado por Elizabeth P. Benson, pp. 145-161, Dumbarton Oaks Research Library and Collections, Washington, D.C.

Engel, Frédéric

1966 Paracas: cien siglos de cultura peruana. Editorial Juan Mejía Baca, Lima.

1991 Un desierto en tiempos prehispánicos: Río Pisco, Paracas, Río Ica. Centro de Investigaciones de Zonas Áridas, Lima.

Frame, Mary

1986 The Visual Images of Fabric Structures in Ancient Peruvian Art. En The Junius B. Bird Conference on Andean Textiles, April $7^{\text {th }}$ and $8^{\text {th }}$, 1994, editado por Ann P. Rowe, pp. 47-8o, The Textile Museum, Washington, DC.

2008 Representaciones de género, jerarquía y otras relaciones en los bordados Paracas Necrópolis. Arqueología y Sociedad 19: 241-264.

King, Mary E.

1965 Textiles and Basketry of the Paracas Period, Ica Valley, Peru. PhD dissertation, Department of Anthropology, University of Arizona. University Microfilms, Tucson.
Lévy Contreras, Jessica

2017 Los apéndices serpentiformes en la iconografía Nasca: repertorio y significado. Tesis de Maestría, Arqueología, Programa de Estudios Andinos, Pontificia Universidad Católica del Perú, Lima.

Lévy Contreras, Jessica y Katherine Román Aquino

2018 El manto pintado Paracas: el legado olvidado de Engel a la arqueología peruana. En Ponencias desarrolladas del I Coloquio de Arqueología del Museo Julio C. Tello de Paracas, 13 y 14 de abril 2018, editado por Katherine Román Aquino, pp. 38-54, Repositorio digital del Ministerio de Cultura del Perú. http://repositorio.cultura.gob.pe/handle/ CULTURA/652

Makowski, Krzysztof

2000 Los seres sobrenaturales en la iconografía Paracas y Nasca. En Los dioses del antiguo Perú, editado por Krzysztof Makowski, Vol, 1, pp. 277-311, Banco de Crédito del Perú, Lima.

2017 Lo real y lo sobrenatural en las iconografías Paracas y Nasca. En Nasca, editado por Cecilia Prado y Peter Fux, pp. 144-153, Museo de Arte de Lima, Lima, Rietberg Museum, Zurich.

Massey, Sarah A.

1986 Sociopolitical Change in the Upper Ica Valley, BC 400 to 400 AD: Regional States on the South Coast of Peru. PhD Dissertation, Department of Archaeology, University of California, Los Angeles.

Menzel, Dorothy, John H. Rowe y Lawrence E. Dawson 1964 The Paracas Pottery of Ica: a Study in Style and Time, University of California Press in American Archaeology and Ethnology, vol. 50, Berkeley, Los Angeles.

Museo Nacional de Antropología, Arqueología e Historia del Perú (MNAAHP)

2013 Paracas. Ministerio de Cultura del Perú, Lima.

O’Neale, Lila M.

1942 Textile Periods in Ancient Peru: II Cavernas and the Grand Necropolis. University of California Publications in American Archaeology and Ethnology 39(2): 143-202.

Paul, Anne

1990 Paracas Ritual Attire: Symbols of Authority in Ancient Peru. University of Oklahoma Press, Norman, London.

Peters, Ann H.

1997 Paracas, Topara and Early Nasca: Ethnicity and Society on the South Central Andean Coast. PhD Dissertation, Department of Anthropology, Cornell University, Ithaca.

2000 Funerary Regalia and Institutions of Leadership in Paracas and Topará. Chungara: Revista de Antropología Chilena 32(2): 245-252. 
2011 Diversidad en el componente textil y modelos de las relaciones sociales: un ejemplo de Paracas Necrópolis. En Actas de las V Jornadas Internacionales sobre Textiles Precolombinos, 29 noviembre - 1 diciembre 2010, pp. 231-256, Universidad Autónoma de Barcelona, Barcelona.

Peters, Ann H. y Elsa Tomasto-Cagigao

2017 Masculities and Feminities: Forms and Expressions of Power in the Paracas Necropolis. En Dressing the Part: Power, Dress, Gender and Representation in the Pre-Columbian Americas, editado por Sarah E. Scher and Billie J. Follensbee, pp. 371-449, University Press of Florida, Gainesville.

Ravines, Roger

1982 Panorama de la arqueología andina. Instituto de Estudios Peruanos, Lima.

Splitstoser, Jeffrey C.

2012 The Parenthetical Notation Method for Recording Yarn Structures. Proceedings of the $13^{\text {th }}$ Biennial Symposium of the Textile Society of America, September 19-22, Paper 745, Washington, D.C. http://digitalcommons.unl.edu/tsaconf/745
Tello, Julio C.

1929 Los descubrimientos del Museo de Arqueología Peruana en la Península de Paracas. Atti del XXII Congresso Internazionale degli Americanisti, Vol. 1: 679-69o, Roma.

1959 Paracas: primera parte. Empresa Gráfica T. Scheuch S.A., Lima.

Tello, Julio C. y Toribio Mejía Xesspe

1979 Paracas: segunda parte: Cavernas y Necrópolis. Universidad Nacional Mayor de San Marcos, Institute of Andean Research of New York, Lima.

Velarde, Leonid

2002-2003 Frederic Engel y la arqueología de la costa sur del Perú. Bulletin de la Société Suisse des Américanistes / Schweizerische AmerikanistenGesellschaft, No. 66-67: 95-98.

Yacovleff, Eugenio y Jorge C. Muelle

1934 Un fardo funerario de Paracas. Revista del Museo Nacional 3(1-2): 63-153.1. 